\title{
Article \\ Maple-Leaf Shaped Broadband Optical Nano-Antenna with Hybrid Plasmonic Feed for Nano-Photonic Applications
}

\author{
Inzamam Ahmad ${ }^{1}$, Shakir Ullah ${ }^{1, *(\mathbb{D})}$, Jalal ud din ${ }^{2}$, Sadiq Ullah ${ }^{1} \mathbb{D}$, Waseem Ullah ${ }^{1}$, Usman Habib $^{3, *(\mathbb{D})}$ \\ Salahuddin Khan ${ }^{4}\left(\mathbb{D}\right.$ and Jaume Anguera ${ }^{5}$
}

1 Department of Telecommunication Engineering, University of Engineering and Technology, Mardan 23200, KP, Pakistan; inziahmad950@gmail.com (I.A.); sadiqullah@uetmardan.edu.pk (S.U.); waseemu402@gmail.com (W.U.)

2 Department of Electrical Engineering, University of Engineering and Technology, Peshawar 25120, KP, Pakistan; jalal6422@gmail.com

3 School of Computer Science and Electronic Engineering, Bangor University, Bangor LL57 2DG, UK

4 College of Engineering, King Saud University, P.O. Box 800, Riyadh 11421, Saudi Arabia; drskhan@ksu.edu.sa

5 Electronics and Telecommunication Department, Universitat Ramon Llull, 08022 Barcelona, Spain; jaume.anguera@salle.url.edu

* Correspondence: shakirhayat.eng@gmail.com (S.U.); u.habib@bangor.ac.uk (U.H.)

\section{check for} updates

Citation: Ahmad, I.; Ullah, S.; din, J.u.; Ullah, S.; Ullah, W.; Habib, U.; Khan, S.; Anguera, J. Maple-Leaf Shaped Broadband Optical Nano-Antenna with Hybrid Plasmonic Feed for Nano-Photonic Applications. Appl. Sci. 2021, 11, 8893. https://doi.org/10.3390/app 11198893

Academic Editor: Anming Hu

Received: 24 August 2021

Accepted: 16 September 2021

Published: 24 September 2021

Publisher's Note: MDPI stays neutral with regard to jurisdictional claims in published maps and institutional affiliations.

Copyright: (c) 2021 by the authors. Licensee MDPI, Basel, Switzerland. This article is an open access article distributed under the terms and conditions of the Creative Commons Attribution (CC BY) license (https:/ / creativecommons.org/licenses/by/ $4.0 /)$.

\begin{abstract}
This article presents a broadband optical nano-antenna, which covers a broader range of optical communication wavelengths (666 to $6000 \mathrm{~nm}$ ), used in nano-photonic applications. The proposed design is modeled and analyzed to obtain a satisfactory gain of up to $11.4 \mathrm{dBi}$ for a single elementbased antenna. The unique feature of the proposed antenna is the hybrid plasmonic waveguide-based feed, which receives the optical signal from the planar waveguide and redirects the signal out of the plane. The proposed antenna provides highly directional radiation properties, which makes it a suitable candidate for inter- and intra-chip optical communications and sensing applications. Moreover, an extension of the work is performed for an array configuration of the order $2 \times 1$ and $64 \times 1$, to increase the gain and directionality. Therefore, this shows that it can be equally useful for optical energy harvesting applications with a significant gain up to $26.8 \mathrm{dBi}$.
\end{abstract}

Keywords: optical nano-antenna; nano-photonic; on-chip optical communication; optical energy harvesting

\section{Introduction}

Antennas have been a significant component for various microwave applications and recent applications of antennas involve transmission in the near-infrared and optical regions. These applications can offer multiple advantages with improved operating conditions, emission control, and light wave radiation into free space [1]. Nature-inspired designs have brought tremendous technological advancements for various applications in recent decades. Antenna geometries based on bio-inspired shapes have been investigated in recent literature, where a flower shape is used to obtain a large bandwidth [2] or a papaya leaf shaped antenna provides a multi-band operation [3]. In terms of antenna array, a four-leaf based antenna is also explored [4] for low frequency applications. The usefulness of the bio-inspired antenna shape for RF applications has been extended to the $\mathrm{GHz}$ band [5], where a vine leaf-based shape is designed on a FR4 substrate. This work explores a similar shape (maple-leaf) for THz photonic applications and investigates it for various design parameters and antenna-array configurations. Nature-inspired designs have shown their feasibility towards a variety of significant frequency ranges. A jasmine flower shaped monopole antenna is presented in [6], which provides a large bandwidth in the sub-6 GHz range frequencies. A triangularis plant's leaf for WiFi frequency range $(2.4 \mathrm{GHz}$ band) is simulated and fabricated in [7] and a snowflake structure for 5G applications is shown in [8]. The use of Fractal geometry to design these shapes is explored in [9], which is used 
by [10] to design a Spiral shell shaped antenna for the multi-band frequency operation. Additionally, it is extended to a dielectric resonator based prototype design in [11].

The optical antenna is a practicable application of physical optics that has the capability of capturing and converting free propagating optical electromagnetic radiation to localized energy and vice versa [12]. These antennas resemble the typical microwave counterparts as they deal with optical fields to confine, transmit, and receive. By making use of the localized surface plasmons (LSP), these antennas can restrain optical (light) waves into very small volumes [13]. The basic principle for that is the induction of free elections by the metal particles due to the illumination of light. These electrons oscillate as a result and, in turn, generate surface charges which change corresponding to the incident light. The aggregations of surface charges that happen on opposite sides of the particles are called surface plasmons (SPs) and they are actually coherent electron oscillations that arise when there is an interface between metal and dielectric [14]. Although optical antennas are strongly analogous to their radio-frequency (RF) and microwave counterparts, their physical properties and scalable behaviors are much different. Most of these differences arise due to the fact that metals are not perfect conductors [15] at optical frequencies. However, they are strongly correlated plasmas, and thus can be described as a free electron gas that can be defined and solved using Drude model equations [16]. For these reasons, modern advancements in nanotechnology and plasmonic technology have generated substantial interest in the optical antenna concept to efficiently overcome the diffraction limit and make it possible to manipulate optical fields on a nanometer scale [17]. The optical nano-antennas can impressively increase the light-matter interaction efficiency, to get a wide range of applications, such as chemical and biological sensing [18], high-resolution microscopy [19], and nanoscale imaging [20]. Additionally, nano-antennas have been considered as efficient and promising elements in photo-detection [21], heat-transfer (thermal ablation of liver and cancer cell) [22], inter-and/or intra-chip optical communications or radio-over-fiber transmission [23], spectroscopy [24], and energy harvesting [25,26].

Several different nano-antenna configurations have been demonstrated so far, such as bow-ties [27], Yagi-Uda [28], cross antennas [29], half-moon shape antenna [30], Crescents [31], and Nanorods [32]. Most of them are with limited bandwidth due to their dipolar type of resonances. Therefore, these configurations are only suitable for narrowband applications. Optical antennas are required to support the broadband operation for a variety of applications. Optical broadband antennas are also exceedingly desirable for fluorescence enhancement, surface-enhanced Raman scattering, and higher harmonic generation, which are intrinsically multi-wavelength and broadband in nature [33]. However, broadband antennas operating in optical frequencies experience limitations such as low radiation efficiency or narrow frequency band operation, etc. [34]. This problem needs to be addressed with an efficient design of a broadband antenna that can provide radiation coverage to the three main frequency windows for optical transmission $(193.1,229$, and $352.9 \mathrm{THz}$ ) to be compatible with commercial nano-photonic applications. In order to be able to receive and transmit optical and infrared signals, a fundamental requirement is to feed the antenna with plasmonic nano-guiding. The wedge plasmon waveguides are superior as compared to groove waveguide structures, due to their strong subwavelength localization of guided plasmonic signals, large propagation distances, and relatively low dissipation [35]. Different types of metallic nanostructures have been proposed for guiding SPP modes, including thin metal films (gold, silver) [36], chains of metal nanoparticles [37], sharp metal wedges [38], etc. The mathematical model of bio-inspired shapes can be obtained using the Gielis formula [39] by transforming multiple superellipses to a leaf or flower shape. The key factor is the use of polar coordinates, along with the use of rotational symmetry to obtain a set of six parameters, which can provide a variety of bio-inspired geometries.

In this manuscript, we propose a broadband optical nano-antenna to achieve high performance in terms of broadband transmission characteristics, fed with a hybrid plasmonic waveguide, and structured according to the nature and landscape-inspired shape of 
a maple leaf. The major contribution of this work is the characteristic design to achieve a high gain at the $\mathrm{THz}$ range and the feasibility to increase it in an array configuration. The bio-inspired shape consists of multiple sharp edges on the radiating patch, which helps the antenna structure resonate on multiple frequencies, thus providing a multi-band operation or obtaining a large bandwidth by covering a range of optical frequencies. The designed antenna in this work has been impedance matched with the characteristic impedance of the waveguide feed and can cover all of the optical communication wavelengths (850, 1310, and $1550 \mathrm{~nm}$ ). The proposed antenna can be used in inter- and intra-chip optical communications and sensing applications. Furthermore, an analysis on the impact of using an array of these designs with $2 \times 1$ and $64 \times 1$ configurations are also presented to achieve a highly directive pattern of $15 \mathrm{dBi}$ gain, in order to enable the designed antenna for the application of energy harvesting.

The rest of the paper is planned in the following order. Section 2 describes the theory of hybrid plasmonic waveguides. Section 3 is concerned with designing the procedure and the geometry of the maple shape nano-antenna. Section 4 presents the simulation results and Section 5 concludes the work.

\section{Structure}

\subsection{Modeling and Characterization of Hybrid Plasmonic Waveguide}

The designed antenna is based on the hybrid plasmonic structure. Figure 1a shows the basic geometry of the waveguide and standpoint view of the final design. Figure $1 \mathrm{~b}$ presents the TM mode of the waveguide. These structures are configured by implementing a material with a low refractive index (such as $\left.\mathrm{SiO}_{2}\right)$, between a metal $(\mathrm{Ag})$ and another material with a higher refractive index (Si). Plasmonic TM modes are the supporting mode, having high confinement inside a low refractive index material [40]. Fundamentally, the hybrid plasmonic waveguide (HPWG) is the combination of dielectric and plasmonic waveguides. Although dielectric waveguides can be considered practically lossless, the mode size in such guides can be limited by the amount of diffraction. On the other hand, plasmonic guides can squeeze light far below the diffraction limit, but consequently cause a large propagation loss. By combining both of these guides, an HPWG can be formed. As compared to purely plasmonic waveguides, HPWG suggests a better compromise between loss and confinement, compatible with silicon on the insulator technology [41]. Different types of waveguides have been analyzed recently. Among these, a hybrid dielectricloaded plasmonic waveguide (HDLPW) has been proposed as a potential candidate for the optical transmission and its waveguide properties were numerically analyzed to verify the principle technique [42]. In [43], the plasmonic slot nano-antenna is shown to provide a 100 times smaller size than the area of the diffraction-limited spot, to control the optical fields at nano-scale.

\subsection{Design of the Nano-Antenna}

The geometry of the proposed novel broadband optical nano-antenna that operates in the infrared and visible window is depicted in Figure 2, in terms of the front and side outlook. The design consists of a landscape-inspired Canadian flag-like antenna of length and width represented as $L$ and $W$, respectively. The antenna is fed by a hybrid plasmonic waveguide which achieves a strong light confinement by coupling the guided light from the dielectric waveguide and plasmonic waveguide. The side view of the antenna in Figure $2 b$ shows that the design comprises three consecutive layers namely metal, low refractive index material, and dielectric having a high refractive index. The low refractive index material is sandwiched between metal and dielectric. The parametric values for the different dimensions shown in the cross-section view of the waveguide are as follows: The thickness of the metallic (Ag) layer, thin $\mathrm{SiO}_{2}$ layer, and the Si layer are defined as $h_{A g}=100 \mathrm{~nm}, h_{S i O 2}=10 \mathrm{~nm}$, and $h_{s i}=100 \mathrm{~nm}$, respectively. The height of the substrate $(h)$ is kept as $200 \mathrm{~nm}$. To cover all of the optical communication windows, we fix our target frequency range of operation as $50-450 \mathrm{THz}$ with the center frequency at 
$\mathrm{fc}_{\mathrm{c}}=250 \mathrm{THz}(\lambda \mathrm{c}=1200 \mathrm{~nm})$. The length $(L)$ and width $(W)$ of the antenna can be calculated using Equations (1)-(6) (where the effective permittivity of Ag is $(-129+3.28 \mathrm{j})$ [38]. Table 1 represents the parametric values used for the simulations to obtain optimum performance of the designed antenna. The impedance of the waveguide is determined as follows:

$$
Z_{\text {waveguide }}=\frac{Z_{0}}{n_{e f f}}=\frac{377}{n_{e f f}}
$$

where the effective refractive index $\left(n_{\text {eff }}\right)$ depends on the permittivity of the medium $\left(\varepsilon_{m}\right)$ and dielectric $\left(\varepsilon_{m}\right)$, as well as, the function of width $(W)$ and thickness of $\mathrm{SiO}_{2}\left(h_{\mathrm{SiO} 2}\right) . Z_{0}$ is the impedance of the free-space (vacuum), equal to $377 \Omega$.

$$
\begin{gathered}
n_{\text {eff }}=\sqrt{\frac{\varepsilon_{m} \varepsilon_{d}}{\varepsilon_{m}+\varepsilon_{d}}} F(W, h) \\
F\left(W, h_{\mathrm{SiO}_{2}}\right)=\frac{1+1798 \mathrm{~W}+311 h_{\mathrm{SiO}_{2}}+10.55 W h_{\mathrm{SiO}_{2}}}{32,300+759.7 \mathrm{~W}+3337 h_{\mathrm{SiO}_{2}}+10.55 W h_{\mathrm{SiO}_{2}}}
\end{gathered}
$$

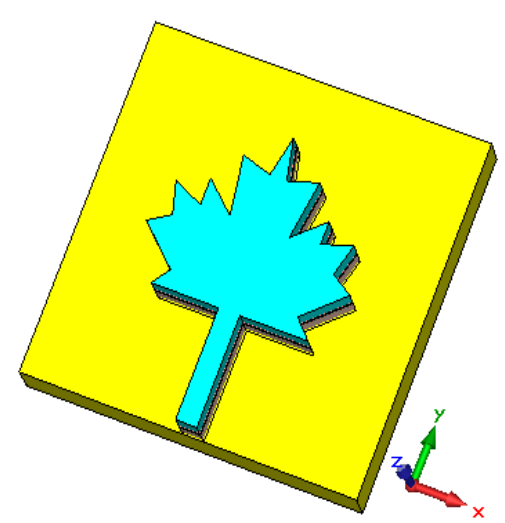

(a)

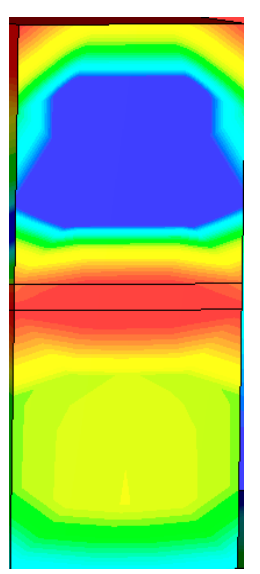

(c)

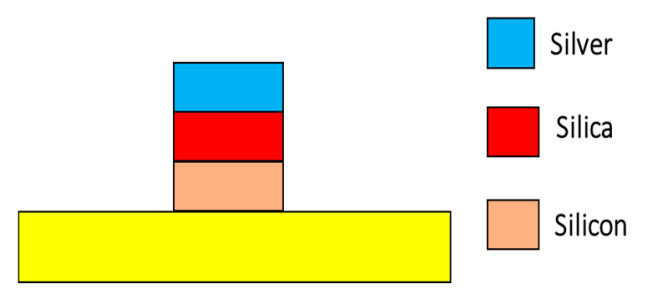

(b)

Figure 1. (a) Perspective view of the structure; (b) basic geometry of HPWG; and (c) TM mode. 


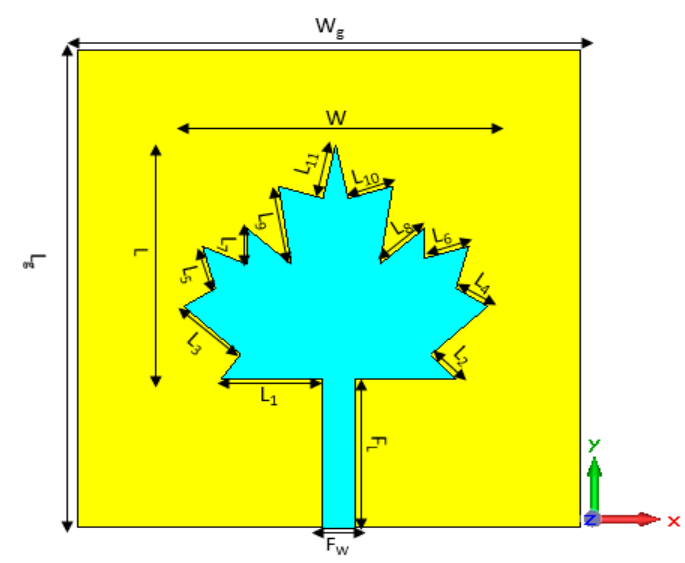

(a)

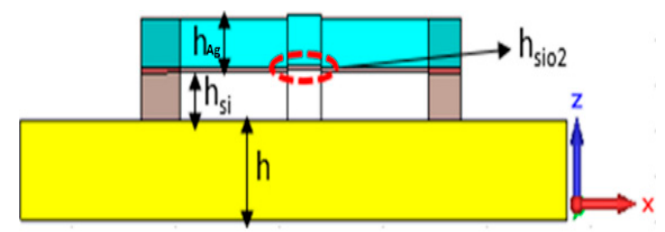

(b)

Figure 2. (a) Front view; (b) side view.

Table 1. Geometric parameters of the proposed design.

\begin{tabular}{cccc}
\hline Parameters & Values $(\mathbf{n m})$ & Parameters & Values (nm) \\
\hline $\mathrm{W}$ & 960 & $\mathrm{~L}_{6}$ & 155 \\
$\mathrm{~L}$ & 780 & $\mathrm{~L}_{7}$ & 125 \\
$\mathrm{~W}_{\mathrm{g}}$ & 1600 & $\mathrm{~L}_{8}$ & 200 \\
$\mathrm{~L}_{\mathrm{g}}$ & 1600 & $\mathrm{~L}_{9}$ & 280 \\
$\mathrm{~F}_{\mathrm{L}}$ & 500 & $\mathrm{~L}_{10}$ & 155 \\
$\mathrm{~F}_{\mathrm{W}}$ & 100 & $\mathrm{~L}_{11}$ & 200 \\
$\mathrm{~L}_{1}$ & 380 & $\mathrm{~h}_{\mathrm{Ag}}$ & 100 \\
$\mathrm{~L}_{2}$ & 115 & $\mathrm{his}$ & 100 \\
$\mathrm{~L}_{3}$ & 250 & $\mathrm{~h}_{\mathrm{SiO} 2}$ & 10 \\
$\mathrm{~L}_{4}$ & 125 & $\mathrm{Hg}$ & 200 \\
$\mathrm{~L}_{5}$ & 155 & $\mathrm{D}$ & 600 \\
$\mathrm{~W}_{\mathrm{A}}$ & 1600 & $\mathrm{~L}_{\mathrm{A}}$ & 3160 \\
\hline
\end{tabular}

Finally, the antenna impedance, in terms of conductance $(G)$ can be found as:

$$
\begin{gathered}
Z_{\text {antenna }}=\frac{1}{Y_{\text {in }}}=\frac{1}{2 G} \\
G=\frac{W}{120 \lambda_{0}}\left[1-\frac{1}{24}\left(\frac{2 \pi h_{\mathrm{SiO}_{2}}}{\lambda_{0}}\right)^{2}\right]
\end{gathered}
$$

where $\lambda_{0}$ is the free-space wavelength. The effective resonant length of the radiating patch is given by:

$$
L=\frac{\lambda_{0}}{2 n_{e f f}}
$$

The development of the design is performed in the steps shown in Figure 3, which produce a different set of return loss characteristics, as will be discussed in the next section. Changes have been made for an improvement in the antenna performance in terms of the driving point impedance bandwidth and the return loss. Figure 3 depicts that step 1 is designed by introducing a rectangular rod, having two triangular cuts on top of the rod with an operating band of 350 and $450 \mathrm{THz}$. In step 2, the patch is embedded with the same-sized rod with a wide band of operating frequency of 50-450 THz. A complete mapleleaf shape is achieved with better results in step 3 having a broadband of $(50-450 \mathrm{THz})$ with the resonance of $193,229,353$, and $390 \mathrm{THz}$. 


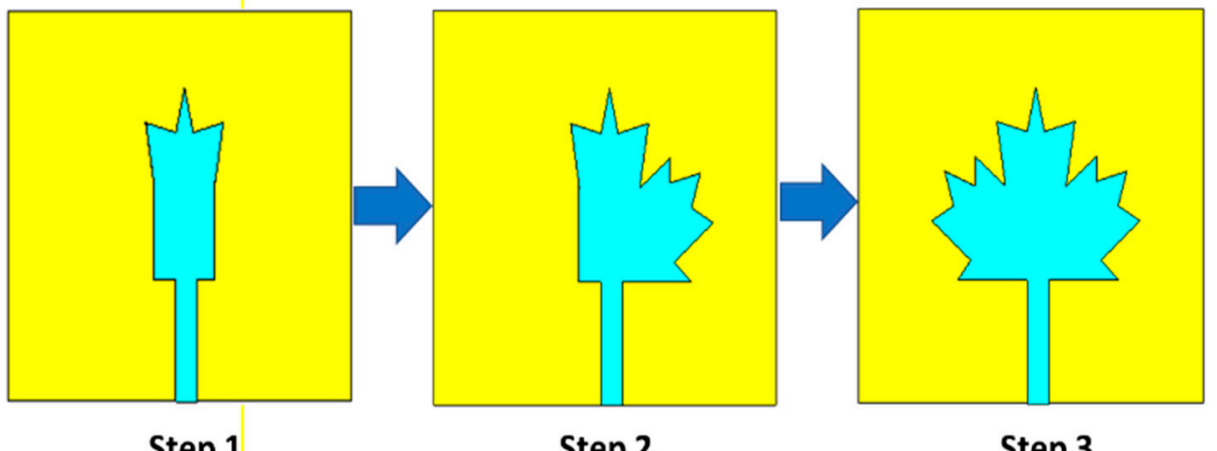

Step 1

Step 2

Step 3

Figure 3. Varied design steps of the proposed antenna.

\section{Simulation and Results}

For a broadband nano-antenna that can operate in the optical and infrared regions to radiate the optical signal into the free space [44], the presented maple-leaf shape nanoantenna is a promising solution. The proposed nano-antenna has been designed and analyzed using the CST Microwave Studio software package [45], which is based on the technique of the finite integration (FI) solver. The return loss for the antenna design at each step (shown in Figure 3) is plotted in Figure 4.

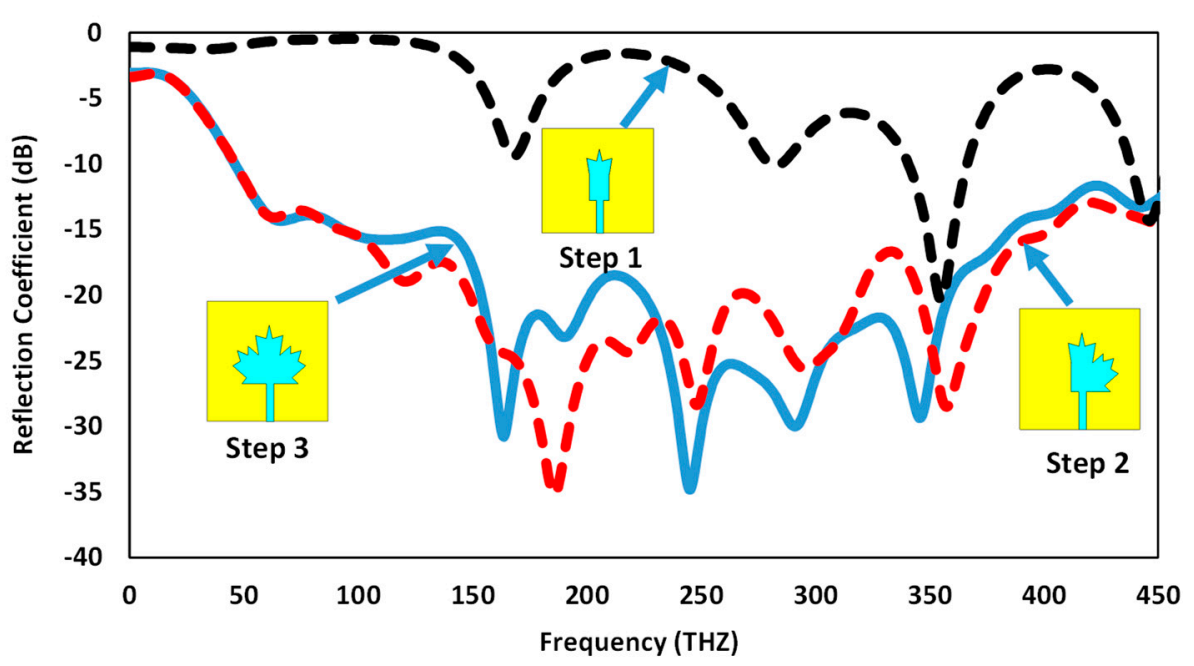

Figure 4. The $S_{11}$ of the design evaluation at each step.

The return loss curve and gain for the final design are plotted against the operational frequency in Figure 5. Here, it can be seen that the antenna operates in all of the three main windows for optical frequencies between 50 to $450 \mathrm{THz}$ with a return loss less than $-10 \mathrm{~dB}$. The second observation from the results is that the gain increases with the frequency, which is very useful to compensate for the high propagation loss at higher frequencies. The voltage standing wave ratio (VSWR) of the proposed broadband nano-antenna is depicted in Figure 6. The VSWR value is between 1 and 1.5 for the frequency band of 50 to $450 \mathrm{THz}$, which is an acceptable value for an antenna operating at these high frequencies. The VSWR value is found to be $1.15,1.18,1.14$, and 1.4 at $193,229,353$, and $390 \mathrm{THz}$, respectively. The maple-shaped antenna is evaluated for different lengths of the leaf tips, as shown in Figure 7. The shape with small leaf tips resonates in multiple frequency bands with the reduced bandwidth. The increase in the leaf tips of a common maple-shape provides better results, but as the length of the leaf tips increases, the dimensions become very narrow and the proposed design will be extremely difficult to be used for real applications, especially in a large array where such small structure details are impossible to achieve. 
The simulation work has been conducted by considering the limitations of the fabrication processes. Therefore, a feasible design is selected for the further analysis.

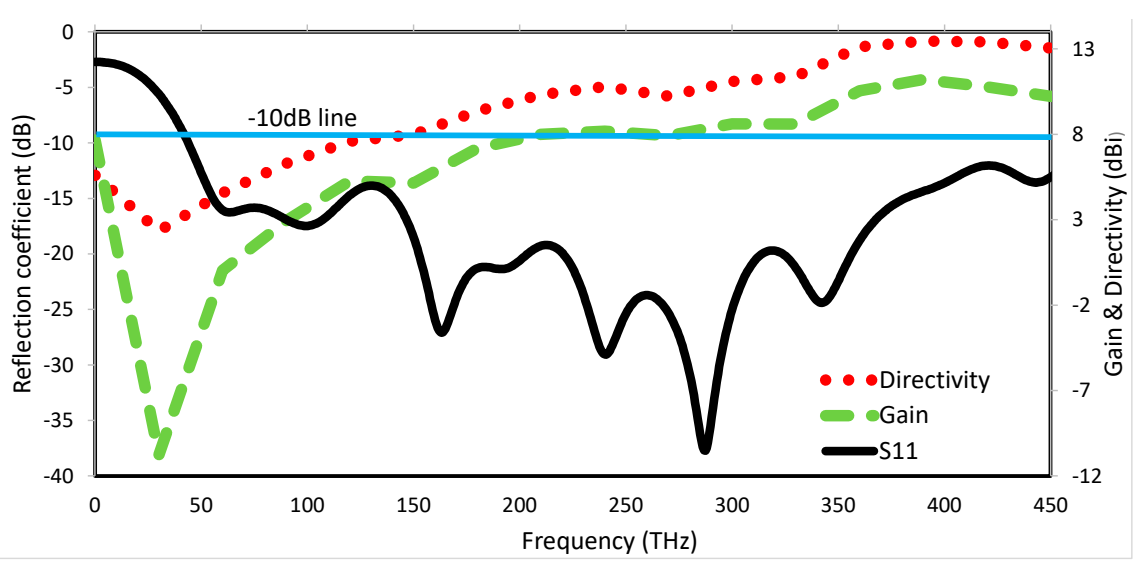

Figure 5. $S_{11}$ and gain of the antenna versus frequency in $\mathrm{THz}$ covering all of the three main optical windows.

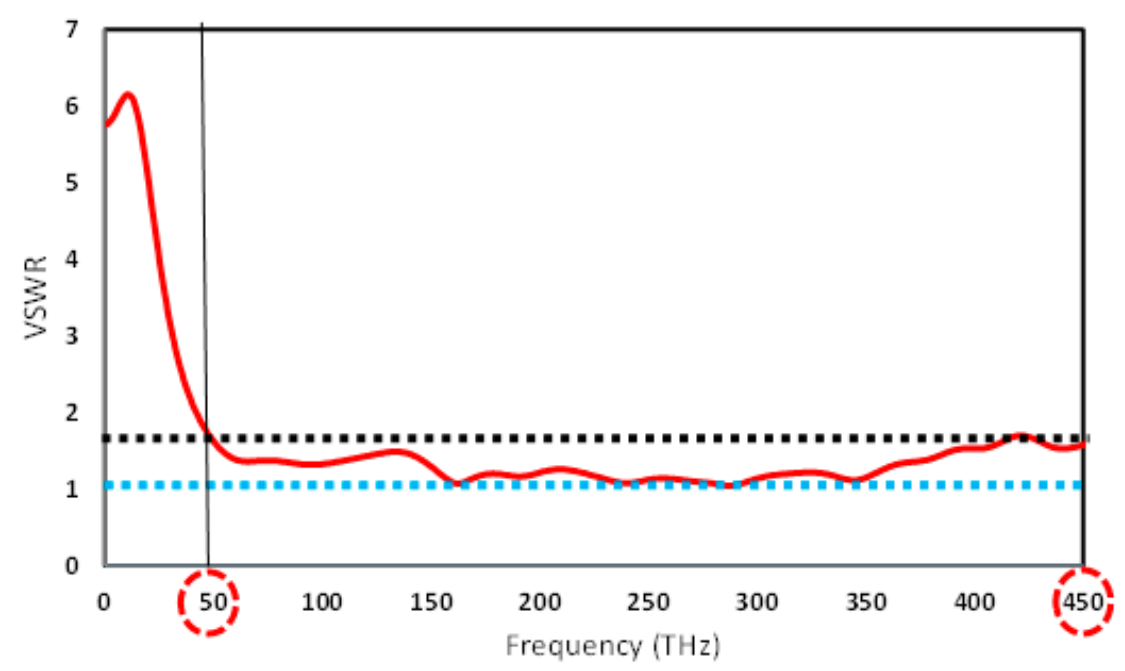

Figure 6. VSWR values for the proposed antenna.

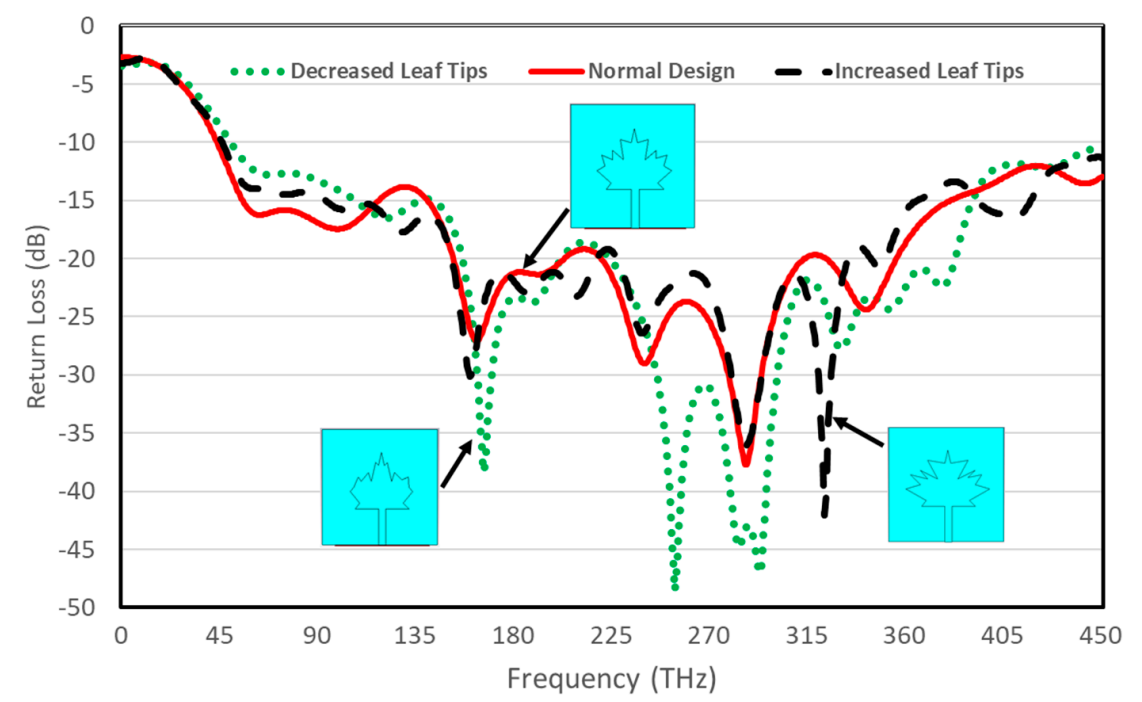

Figure 7. Performance comparison for different lengths of the leaf tips with the maple-leaf antenna geometry shown as an inset. 
The polar plot and 3D radiation pattern for the simulated broadband nano-antenna are shown in Figures 8 and 9, respectively. The simulation results show that the proposed optical antenna directs the optical signal at $0^{\circ}$ with the half-power beamwidth (HPBW) of 49.5, $41.4,32.8$, and $26.4^{\circ}$, while operating at a frequency of $193,229,353$, and $390 \mathrm{THz}$, respectively. From these values, it can be concluded that as the transmitting frequency increases, the beamwidth of the antenna narrows down, and the antenna becomes more directive.

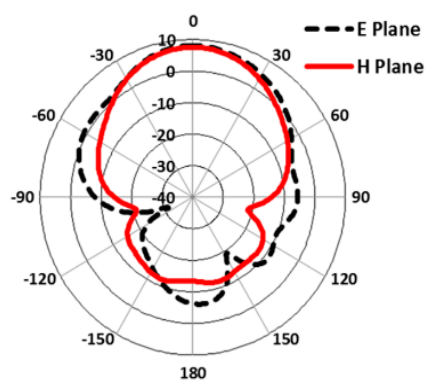

(a)

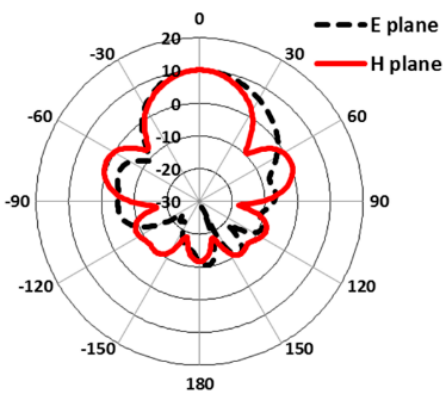

(c)

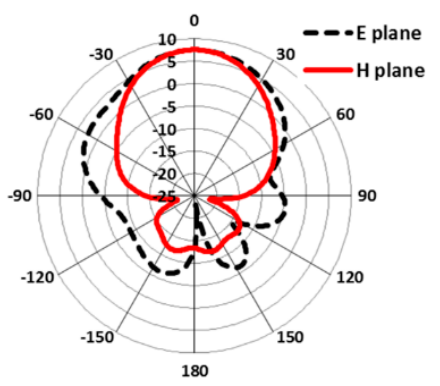

(b)

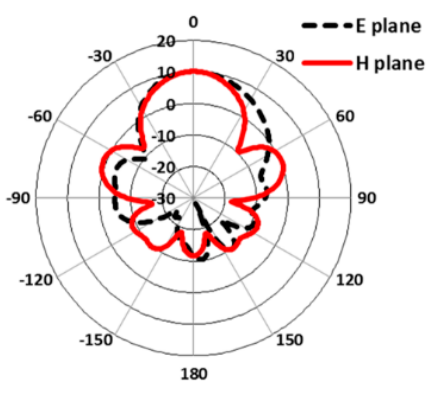

(d)

Figure 8. Gain plot in the E and H planes at (a) $193 \mathrm{THz}$; (b) $229 \mathrm{THz}$; (c) $353 \mathrm{THz}$; (d) $390 \mathrm{THz}$.
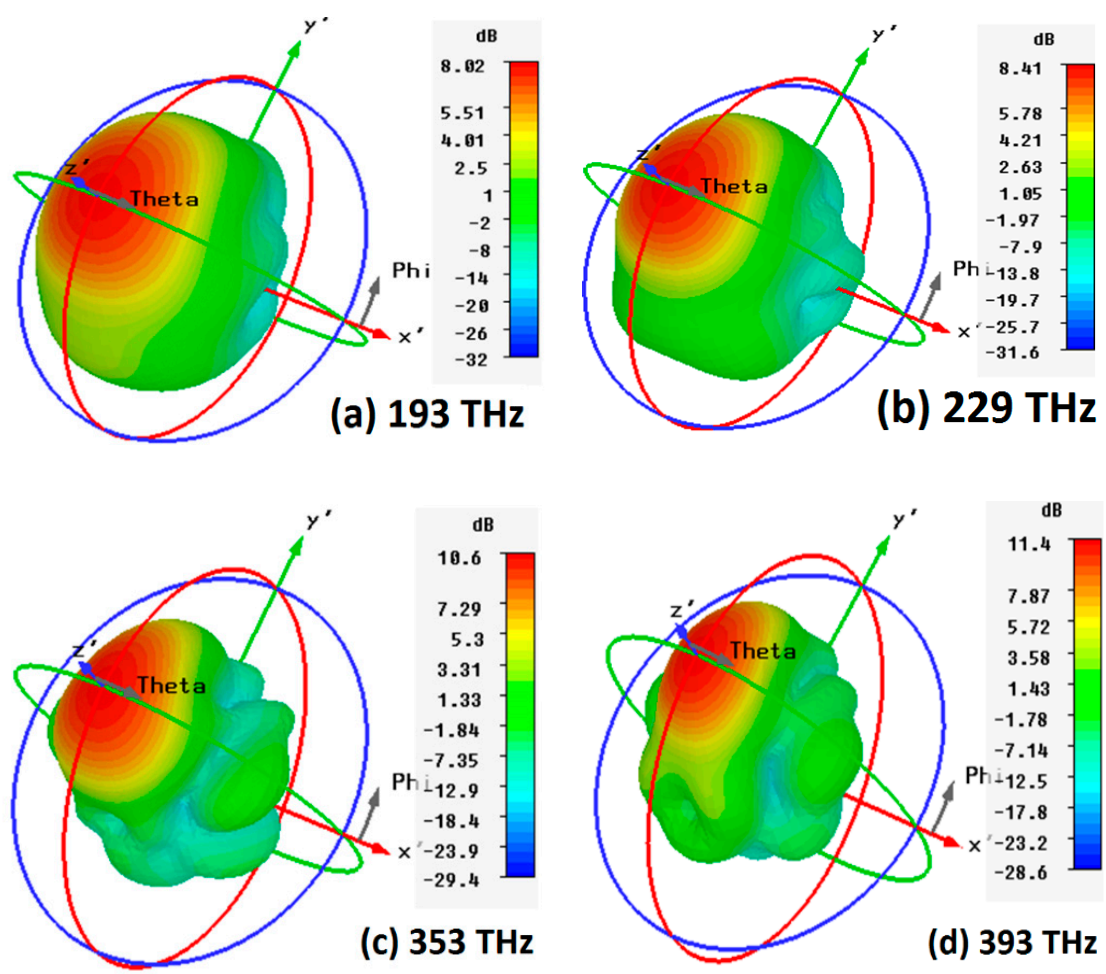

Figure 9. Three-dimensional far-field gain pattern for the designed antenna at (a) $193 \mathrm{THz}$ (b) $229 \mathrm{THz}$ (c) $353 \mathrm{THz}$ and (d) $393 \mathrm{THz}$ 
To observe the resonant area, surface electric fields (E field) recorded at the resonance frequency of $193 \mathrm{THz}$ are indicated in Figure 10, where the upper and lower edge of the maple-leaf shaped broadband antenna show more intensity than the central region. The effective resonant area is highlighted in Figure 11 for the surface current distributions of the proposed nano-antenna. As expected, at the resonance frequency of $193 \mathrm{THz}$, most of the current density is concentrated at the central area of the antenna.

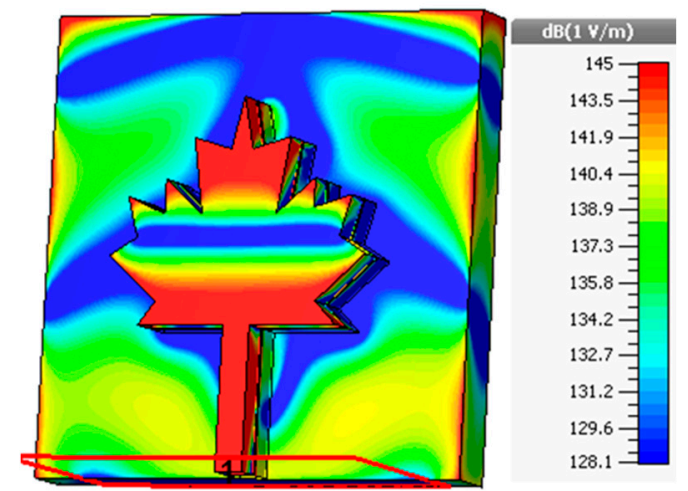

Figure 10. Electric field surface plot of the maple-shaped nano-antenna.

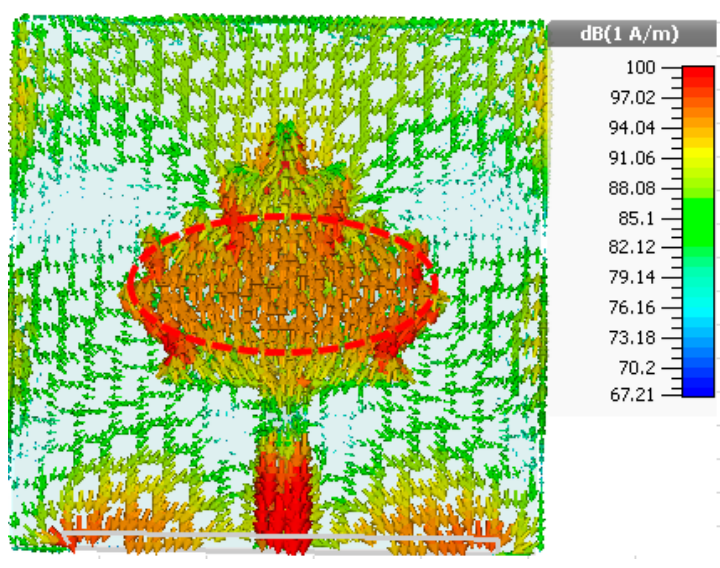

Figure 11. Surface current plot for the maple shape.

\section{Antenna Array for Energy Harvesting Applications}

An extraordinary amount of work has been done in the field of energy harvesting applications through antennas in the last decade, to minimize the huge consumption of fossil fuel [46]. For energy harvesting applications, the antenna must have a high gain and radiation efficiency, which can be attained by making an array of several antennas [47]. The idea of collecting solar energy from the sun's and earth's radiation using nano-antennas is based on the fact that when a light source impinges the surface of a nano-antenna, the surface plasmons resonate and a time-varying current is induced on the antenna's surface. This phenomenon generates a voltage at the feeding point of the antenna. The induced electric field is then transferred via a feeding line and converted into an electric current to be supplied to a load [48]. By designing a $2 \times 1$ array from the aforementioned nano-antenna, a good amount of improvement can be achieved in terms of gain and directivity. The array design for a basic $2 \times 1$ configuration is shown in Figure 12, where for a single array with multiple elements, the spacing $\mathrm{D}$ is an important parameter that defines the main behavior of the array. The return loss and gain of a single element and $2 \times 1$ array are plotted in Figure 13 for comparison. The figure shows that increasing the elements in the array provides a higher gain, but the frequency response of the antenna slightly changes due to the dependence on the value of D. However, both configurations work in the large optical frequency span and can be considered for energy harvesting applications. 


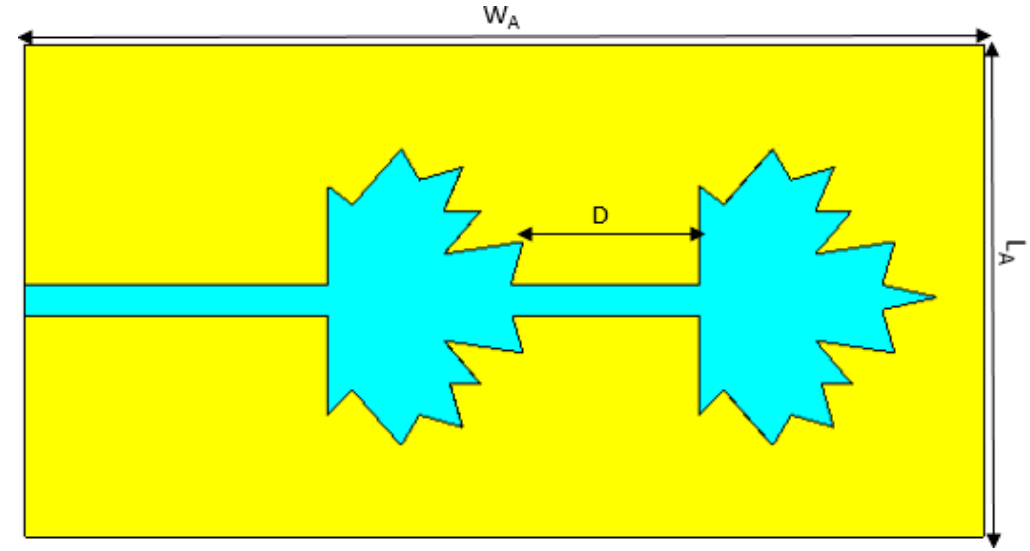

Figure 12. Front view for the $2 \times 1$ antenna array.

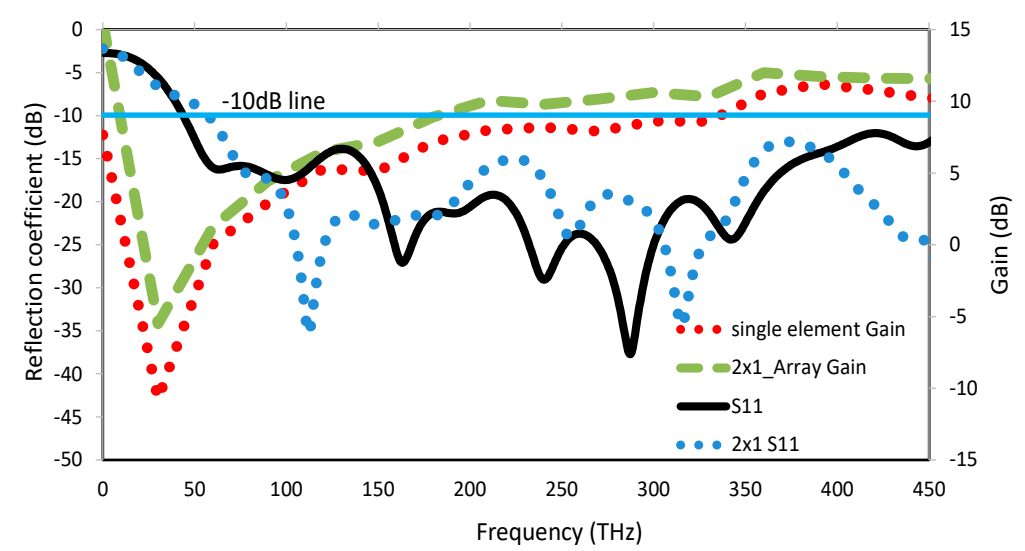

Figure 13. $\mathrm{S}_{11}$ and gain comparison of the single element and $2 \times 1$ array.

As the spacing between the two array elements needs to be carefully optimized, an analysis is performed to show the impact on the return loss. Figure 14 shows the change in response of the designed antenna for different antenna spacing values (D). For a maximum transmission frequency of $450 \mathrm{THz}$, the results shown previously in Figure 13 are plotted when $\mathrm{D}=600 \mathrm{~nm}$ is approximately equal to $\lambda$. The results for $\mathrm{D}=\lambda / 2$ show a poor return loss and an increase in $\mathrm{D}$ to a value of $1.5 \lambda$ shows a very low bandwidth operation, which is not suitable for $\mathrm{THz}$ applications. Therefore, $\mathrm{D}$ of $600 \mathrm{~nm}$ is selected for the further analysis and Figure 15 shows the radiation efficiency for the $2 \times 1$ array. The polar plot and 3 D radiation graphs of the $2 \times 1$ array are shown in Figures 16 and 17, respectively.

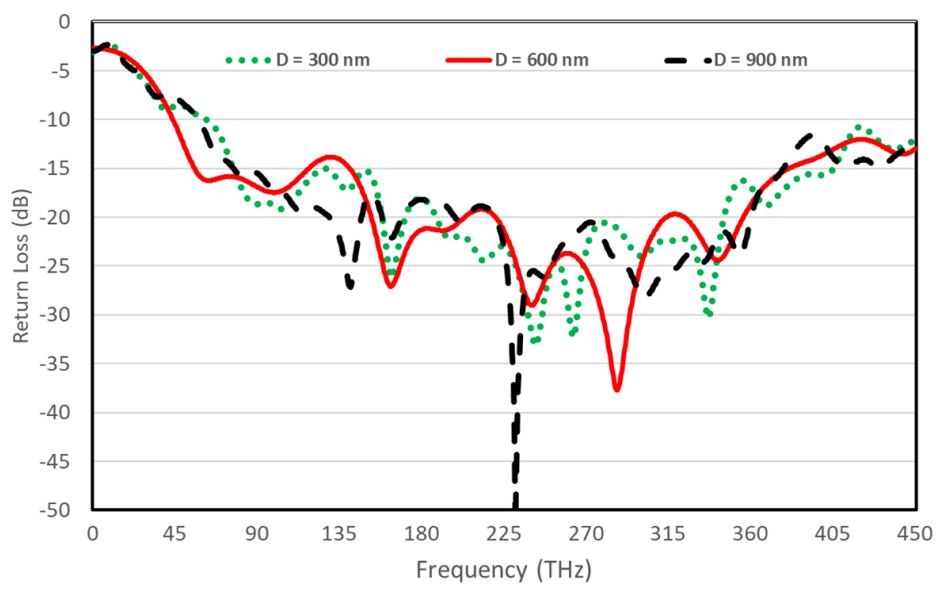

Figure 14. Performance comparison for various spacings between the elements in the $2 \times 1$ array design. 


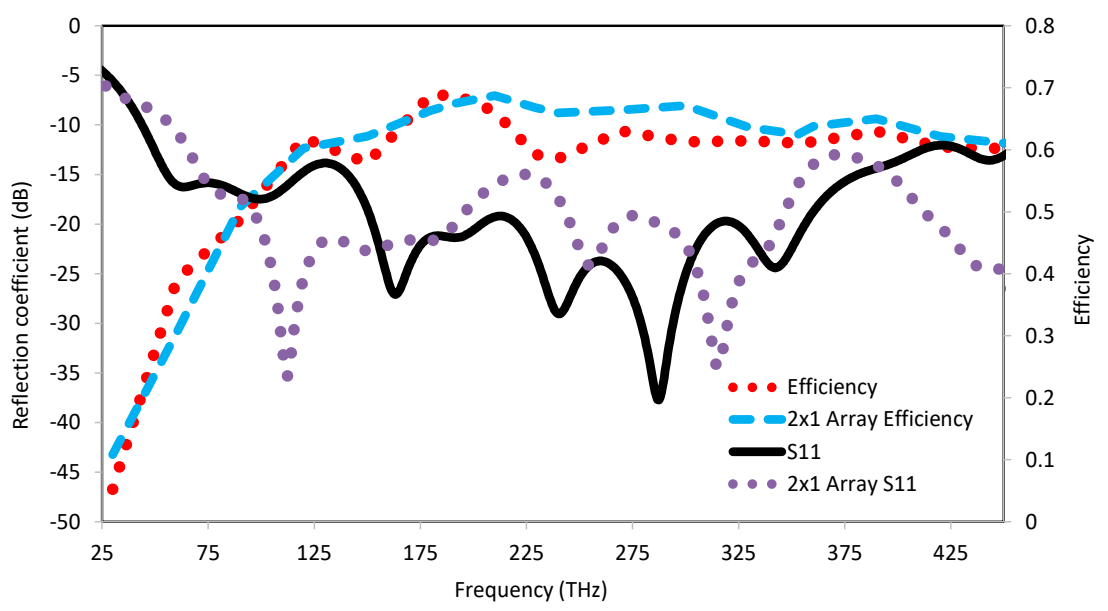

Figure 15. Radiation efficiency for the $2 \times 1$ antenna array.

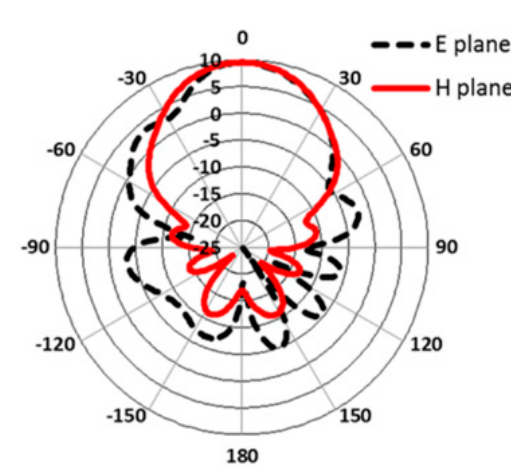

(a) $193 \mathrm{THz}$

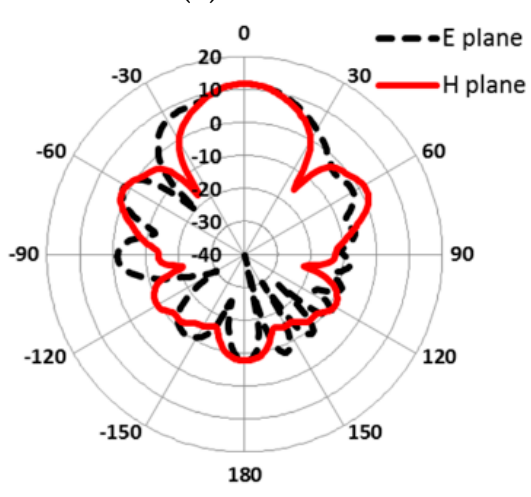

(c) $353 \mathrm{THz}$

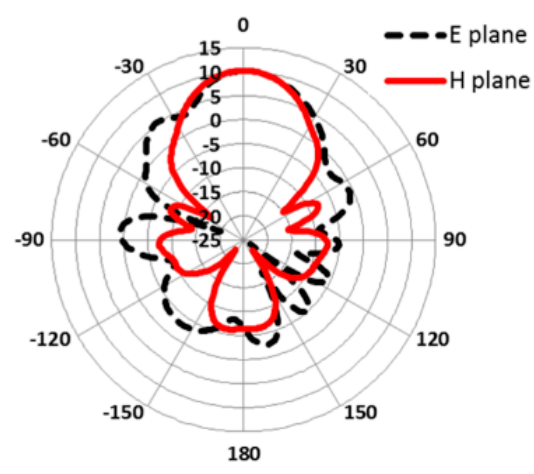

(b) $229 \mathrm{THz}$

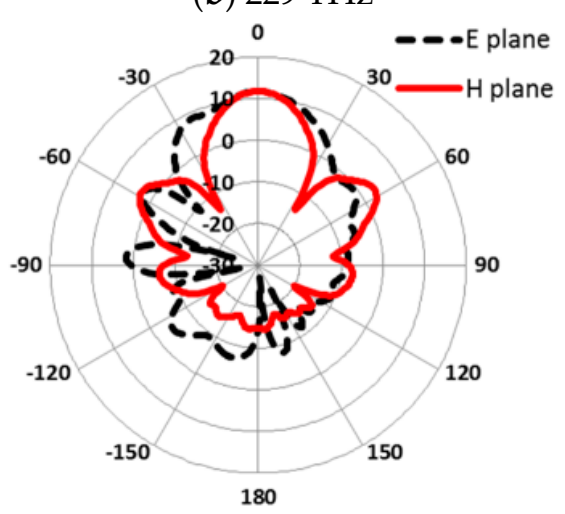

(d) $390 \mathrm{THz}$

Figure 16. The $2 \times 1$ array gain plots in the $\mathrm{E}$ and H planes at (a) $193 \mathrm{THz}$; (b) $229 \mathrm{THz}$; (c) $353 \mathrm{THz}$; (d) $390 \mathrm{THz}$. 

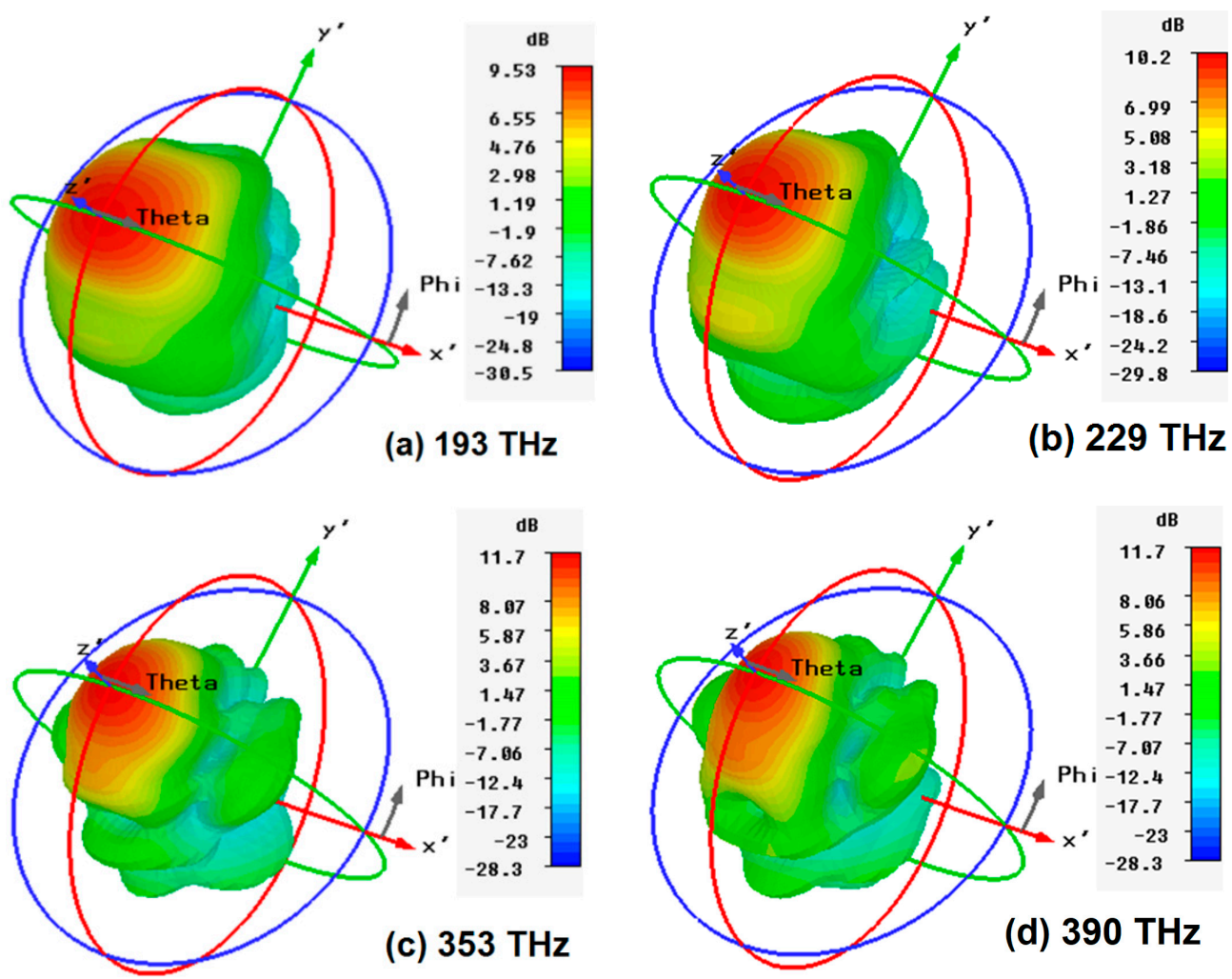

Figure 17. The $2 \times 1$ array 3D far field gain pattern at (a) $193 \mathrm{THz}$; (b) $229 \mathrm{THz}$; (c) $353 \mathrm{THz}$; (d) $390 \mathrm{THz}$.

Researchers have designed various antennas for nano-photonics applications. The proposed antenna has a higher gain and directivity to fully fill the same application compared with the state-of-the-art published work in Table 2.

Table 2. Comparison of the proposed antenna with the existing antennas.

\begin{tabular}{cccccccc}
\hline References & [47] & [44] & [49] & [50] & [51] & [52] & This Work \\
\hline Frequency (THz) & $193.5 / 229 / 352.9$ & 193.5 & $193.5 / 229 / 352.9$ & 193.5 & 193.5 & 193.5 & $193.5 / 229 / 352.9 / 393$ \\
Gain (dBi) & $5.03 / 4.64 / 2.02$ & 5.6 & $4.67 / 4.8 / 7.26$ & 7.99 & 7.5 & 9 & $8.02 / 8.41 / 10.6 / 11.4$ \\
Efficiency (\%) & $* * *$ & 87 & $* * *$ & 84.56 & $* * *$ & 89 & 60 \\
Bandwidth (GHz) & 234 & 15.6 & 240 & 203 & 20 & 40 & 400 \\
\hline
\end{tabular}

*** Not Given

As the simulation analysis shows an increase in gain and directivity with the increase in the number of antenna elements, the higher-order array size is required to achieve a gain above $20 \mathrm{dBi}$. By performing the calculations using the array tool kit in CST MWS, which uses the array factor formula [53] to calculate the array pattern from a single nano-antenna, a $64 \times 1$ array is required to achieve a $3 \mathrm{~dB}$ bandwidth gain of $20 \mathrm{dBi}$. The polar plot and 3D radiation pattern of the $64 \times 1$ element array are depicted in Figures 18 and 19, which show that the beam width becomes narrower and a peak gain of about $26 \mathrm{dBi}$ can be achieved. Table 3 presents a summary of the results with the single, $2 \times 1$, and $64 \times 1$ array nano-antennas for comparison. 


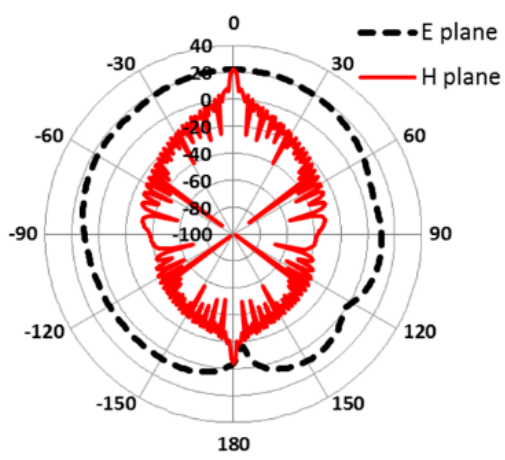

(a) $193 \mathrm{THz}$

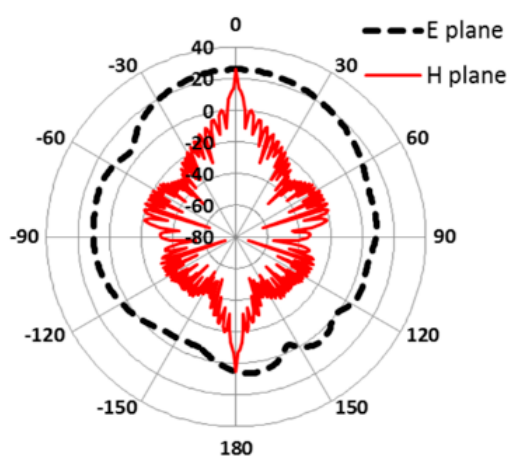

(c) $353 \mathrm{THz}$

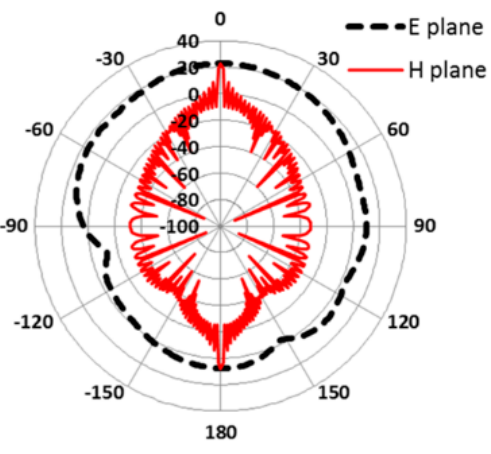

(b) $229 \mathrm{THz}$

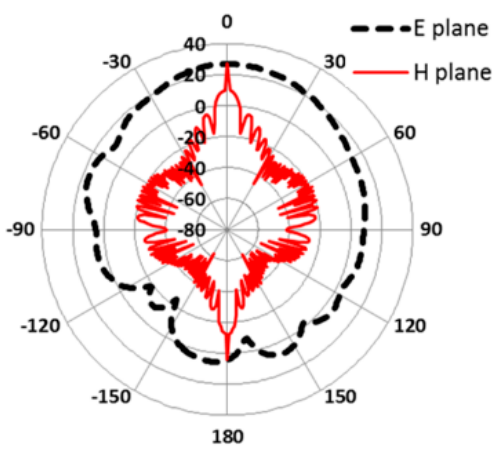

(d) $390 \mathrm{THz}$

Figure 18. The $64 \times 1$ array gain plots in the $\mathrm{E}$ and $\mathrm{H}$ planes at (a) $193 \mathrm{THz}$; (b) $229 \mathrm{THz}$; (c) $353 \mathrm{THz}$; (d) $390 \mathrm{THz}$.
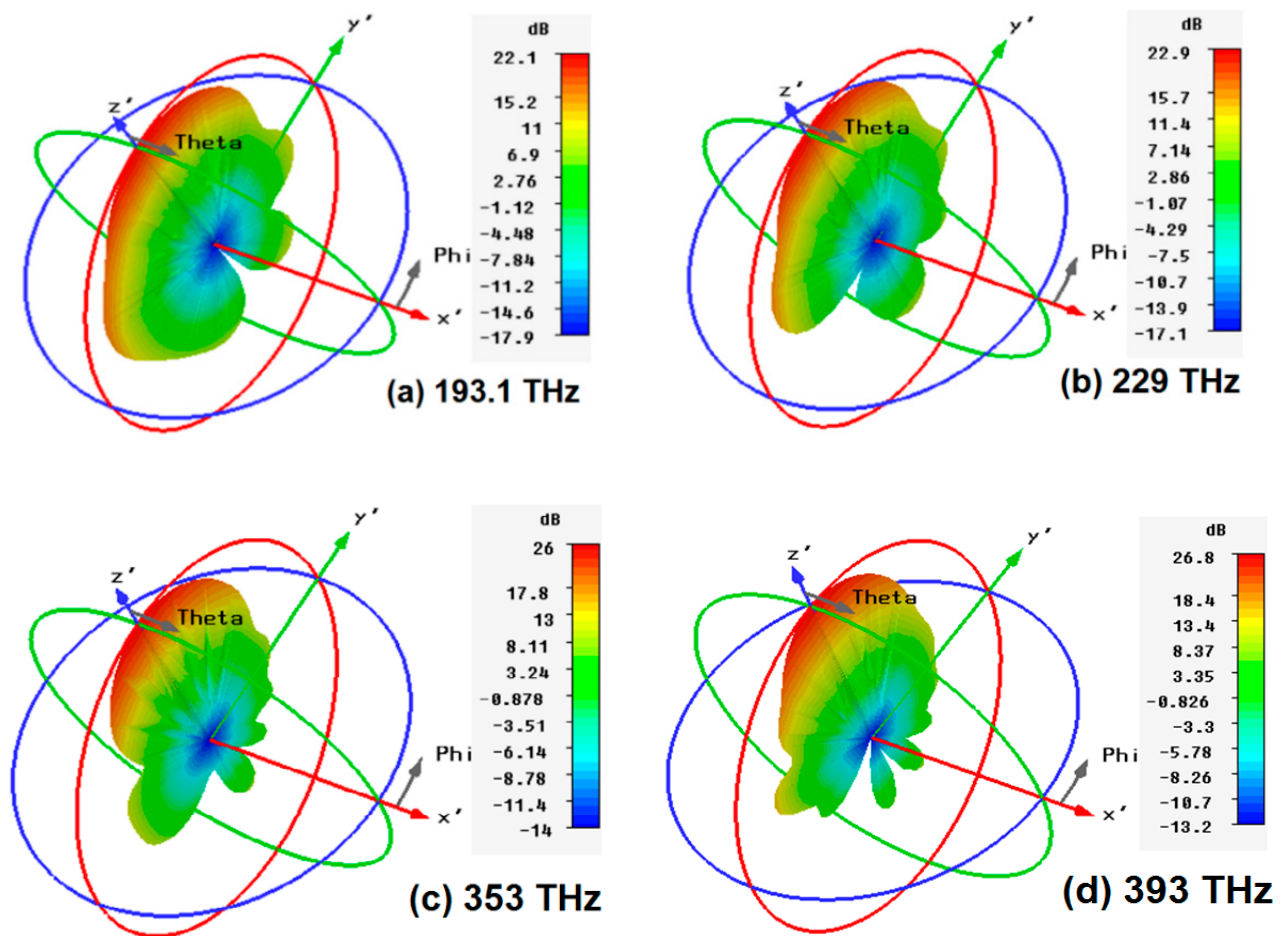

Figure 19. The $64 \times 1$ array 3D far field gain pattern at (a) $193 \mathrm{THz}$; (b) $229 \mathrm{THz}$; (c) $353 \mathrm{THz}$; (d) $390 \mathrm{THz}$. 
Table 3. Summary of the overall results of gain and directivity.

\begin{tabular}{cccc}
\hline Parameter & \multicolumn{3}{c}{ Gain (dBi) } \\
\hline Frequency (THz) & Single Element & $\mathbf{2} \times \mathbf{1}$ Array & $\mathbf{6 4} \times \mathbf{1}$ Array \\
\hline 193 & $8.02 / 9.65$ & $9.53 / 11.2$ & $22.1 / 23.7$ \\
229 & $8.41 / 10.7$ & $10.2 / 11.9$ & $22.9 / 25.1$ \\
353 & $10.6 / 12.7$ & $11.7 / 13.8$ & $26 / 28.1$ \\
390 & $11.4 / 13.5$ & $11.7 / 13.8$ & $26.8 / 28.8$ \\
\hline
\end{tabular}

\section{Conclusions}

In this paper, a nature-inspired maple-leaf shaped optical nano-antenna is presented and fed with a hybrid plasmonic waveguide (HPW) to achieve a high gain with a broadband operation. The optimization of the proposed design provides a high gain of $11.8 \mathrm{dBi}$ at THz frequencies and a bandwidth of $400 \mathrm{GHz}$. Moreover, the antenna is explored to operate in an array structure $(2 \times 1$ and $64 \times 1)$, in order to be used for optical energy harvesting applications with a satisfactory performance and gain above $26 \mathrm{dBi}$. The proposed design shows the ability to operate over a broad range of optical frequencies as shown by the simulation results, by covering all of the key optical communication band ranges from 660 to $6000 \mathrm{~nm}$. Therefore, this design can be integrated with applications such as optical wireless communications in inter- and intra-chip devices and sensing.

Author Contributions: Conceptualization, I.A., S.U. (Shakir Ullah), and U.H.; data curation, J.u.d.; formal analysis, I.A., W.U. and S.U. (Sadiq Ullah); funding acquisition, S.K. and J.A.; methodology, I.A., S.U. (Shakir Ullah), J.u.d. and U.H.; project administration, S.K.; resources, J.A. and S.U. (Sadiq Ullah); software, S.U. (Shakir Ullah); supervision, S.U. (Sadiq Ullah); validation, W.U.; writingoriginal draft, U.H.; writing — review and editing, S.K. and J.A. All authors have read and agreed to the published version of the manuscript.

Funding: This work has been funded by King Saud University, Riyadh, Saudi Arabia through Researchers Supporting Project number (RSP-2021/58).

Institutional Review Board Statement: Not applicable.

Informed Consent Statement: Not applicable.

Data Availability Statement: Not applicable.

Acknowledgments: The authors sincerely appreciate funding from Researchers Supporting Project number (RSP-2021/58), King Saud University, Riyadh, Saudi Arabia.

Conflicts of Interest: The authors declare no conflict of interest.

\section{References}

1. Ullah, S.; Ahmad, I.; Raheem, Y.; Ullah, S.; Ahmad, T.; Habib, U. Hexagonal shaped CPW feed based frequency reconfigurable antenna for WLAN and sub-6 GHz 5G applications. In Proceedings of the IEEE 2020 International Conference on Emerging Trends in Smart Technologies (ICETST), Karachi, Pakistan, 26-27 March 2020; pp. 1-4.

2. Panda, R.A.; Kumari, P.; Naik, J.; Negi, P.; Mishra, D. Flower Shaped Patch with Circular Defective Ground Structure for $15 \mathrm{GHz}$ Application. In International Conference on Innovations in Bio-Inspired Computing and Applications; Springer: Cham, Switzerland, 2019; pp. 243-249.

3. Abolade, J.O.; Konditi, D.B.O.; Dharmadhikary, V.M. Bio-inspired wideband antenna for wireless applications based on perturbation technique. Heliyon 2020, 6, e04282. [CrossRef]

4. De Oliveira, M.A.; da Costa, A.P.; Forte, G.G.S.; de Melo, P.-K.P.; Fontgalland, G.; Silva, P.-H.F.; Fontgalland, I.L. Using polar transformation to design a dissimilar antenna array inspired on four-leaf clover. In Proceedings of the 2018 IEEE Radio and Wireless Symposium (RWS), Anaheim, CA, USA, 15-18 January 2018; pp. 228-230.

5. Abolade, J.O.; Konditi, D.B.; Dharmadhikary, V.M. Compact Vitis vinifera-Inspired Ultrawideband Antenna for High-Speed Communications. Int. J. Antennas Propag. 2021, 2021, 9975884. [CrossRef]

6. da Silva Júnior, P.F.; Carlos, R.; Freire, S.; René Serres, A.J.; da Fonseca Silva, P.H.; Costa Silva, J. Bio-Inspired Antenna for UWB Systems. In Proceedings of the 2016 1st International Symposium on Instrumentation Systems, Circuits and Transducers (INSCIT), Belo Horizonte, Brazil, 29 August 2016-3 September 2016; p. 16408466. 
7. Mesquita, M.D.S.; D’Assunção, A.G.; Oliveira, J.B.L.; Batista, Y.M.V. A New Conductive Ink for Microstrip Antenna and Bioinspired FSS Designs on Glass and Fiberglass Substrates. J. Microw. Optoelectron. Electromagn. Appl. 2019, 18, $227-245$. [CrossRef]

8. Malik, R.; Singh, P.; Ali, H.; Goel, T. A Star Shaped Superwide Band Fractal Antenna for 5G Applications. In Proceedings of the 2018 3rd International Conference for Convergence in Technology (I2CT), Pune, India, 6-8 April 2018; pp. 1-6.

9. Anguera, J.; Puente, C.; Borja, C.; Soler, J. Fractal-Shaped Antennas: A Review. In Wiley Encyclopedia of RF and MicrowaveEngineering; Chang, K., Ed.; JohnWiley \& Sons, Inc.: New York, NY, USA, 2005; Volume 2, pp. 1620-1635.

10. Melchiorre, L.; Marasco, I.; Niro, G.; Basile, V.; Marrocco, V.; D’Orazio, A.; Grande, M. Bio-Inspired Dielectric Resonator Antenna for Wideband Sub-6 GHz Range. Appl. Sci. 2020, 10, 8826. [CrossRef]

11. Marrocco, V.; Basile, V.; Marasco, I.; Niro, G.; Melchiorre, L.; D’Orazio, A.; Grande, M.; Fassi, I. Rapid Prototyping of Bio-Inspired Dielectric Resonator Antennas for Sub-6 GHz Applications. Micromachines 2021, 12, 1046. [CrossRef]

12. Bharadwaj, P.; Deutsch, B.; Novotny, L. Optical antennas. Adv. Opt. Photonics 2009, 1, 438-483. [CrossRef]

13. Duman, H. Design and Fabrication of Resonant Nanoantennas on Chalcogenide Glasses for Nonlinear Photonic Applications; Bilkent University: Ankara, Turkey, 2013.

14. Yuming, W. Analysis and Design of Nanoantennas. Ph.D. Dissertation, National University of Singapore, Singapore, 2010.

15. Haroyan, H.S.; Tadevosyan, V.R. High Gain Broadband Plasmonic Slot Nano-Antenna. Int. J. Phys. Math. Sci. 2015, 9, 1104-1107.

16. Sethi, W.T.; Vettikalladi, H.; Fathallah, H.; Himdi, M. Hexagonal dielectric loaded nantenna for optical ITU-T C-band communication. In Proceedings of the 2015 IEEE 11th International Conference on Wireless and Mobile Computing, Networking and Communications (WiMob), Abu Dhabi, United Arab Emirates, 19-21 October 2015; pp. 604-607.

17. Zhou, R.; Ding, J.; Arigong, B.; Lin, Y.; Zhang, H. Design of a new broadband monopole optical nano-antenna. J. Appl. Phys. 2013, 114, 184305. [CrossRef]

18. Kausar, A.S.M.Z.; Reza, A.W.; Latef, T.A.; Ullah, M.H.; Karim, M.E. Optical nano antennas: State of the art, scope and challenges as a biosensor along with human exposure to nano-toxicology. Sensors 2015, 15, 8787-8831. [CrossRef]

19. Rosner, B.; Peck, J.; van der Weide, D. Near-field antennas integrated with scanning probes for THz to visible microscopy: Scale modeling and limitations on performance. IEEE Trans. Antennas Propag. 2002, 50, 670-675. [CrossRef]

20. Xu, T.; Wu, Y.-K.; Luo, X.; Guo, L.J. Plasmonic nanoresonators for high-resolution colour filtering and spectral imaging. Nat. Commun. 2010, 1, 59. [CrossRef] [PubMed]

21. Tang, L.; Kocabas, S.E.; Latif, S.; Okyay, A.K.; Ly-Gagnon, D.S.; Saraswat, K.C.; Miller, D.A. Nanometre-scale germanium photodetector enhanced by a near-infrared dipole antenna. Nat. Photonics 2008, 2, 226-229. [CrossRef]

22. Rabienejhad, M.J.; Mazaheri, A.; Davoudi-Darareh, M. Design and optimization of nano-antenna for thermal ablation of liver cancer cells. Chin. Phys. B 2021, 30, 048401. [CrossRef]

23. Habib, U.; Aighobahi, A.; Wang, C.; Gomes, N.J. Radio over fiber transport of mm-Wave $2 \times 2$ MIMO for spatial diversity and multiplexing. In Proceedings of the IEEE International Topical Meeting on Microwave Photonics (MWP), Long Beach, CA, USA, 31 October 2016-3 November 2016; pp. 39-42.

24. Tapio, K.; Mostafa, A.; Kanehira, Y.; Suma, A.; Dutta, A.; Bald, I. A Versatile DNA Origami-Based Plasmonic Nanoantenna for Label-Free Single-Molecule Surface-Enhanced Raman Spectroscopy. ACS Nano 2021, 15, 7065-7077. [CrossRef] [PubMed]

25. Liu, Y.; Li, K.; Cao, S.; Xiong, G.; Zhu, L. Optimization Design of a Multi-slot Nanoantenna Based on Genetic Algorithm for Energy Harvesting. Plasmonics 2019, 14, 1577-1586. [CrossRef]

26. Mora-Ventura, B.; Sánchez, J.E.; González, G.; González, F.J. Thermal impedance analysis of nano-dipole linear arrays for energy harvesting applications. Infrared Phys. Technol. 2020, 107, 103332. [CrossRef]

27. Wu, Y.-M.; Li, L.-W.; Liu, B. Gold bow-tie shaped aperture Nanoantenna: Wide band near-field resonance and far-field radiation. IEEE Trans. Magn. 2010, 46, 1918-1921. [CrossRef]

28. Miroshnichenko, A.E.; Maksymov, I.S.; Davoyan, A.R.; Simovski, C.; Belov, P.; Kivshar, Y.S. An arrayed nanoantenna for broadband light emission and detection. Phys. Status Solidi (RRL)-Rapid Res. Lett. 2011, 5, 347-349. [CrossRef]

29. Biagioni, P.; Huang, J.S.; Duò, L.; Finazzi, M.; Hecht, B. Cross Resonant Optical Antenna. Phys. Rev. Lett. 2009, $102,256801$. [CrossRef] [PubMed]

30. Ahmad, I.; Ullah, S.; Ullah, S.; Habib, U.; Ahmad, S.; Ghaffar, A.; Alibakhshikenari, M.; Khan, S.; Limiti, E. Design and Analysis of a Photonic Crystal Based Planar Antenna for THz Applications. Electronics 2021, 10, 1941. [CrossRef]

31. Zainud-Deen, S.H.; Malhat, H.A.; El-Refaay, E.A. Polarization-Independent Reconfigurable Graphene Gas Sensor Using Crescent Plasmonic Antenna. Plasmonics 2020, 15, 1115-1122. [CrossRef]

32. Dong, Z.; Sun, C.; Si, J.; Deng, X. A tunable plasmonic nano-antenna based on metal-graphene double-nanorods. Laser Phys. Lett. 2018, 15, 056202. [CrossRef]

33. Yong, Z.; Gong, C.; Dong, Y.; Zhang, S.; He, S. Broadband localized electric field enhancement produced by a single-element plasmonic nanoantenna. RSC Adv. 2017, 7, 2074-2080. [CrossRef]

34. Iluz, Z.; Boag, A. Wideband dual Vivaldi nano-antenna with high radiation efficiency over the infrared frequency band. In Proceedings of the 2011 IEEE International Conference on Microwaves, Communications, Antennas and Electronics Systems (COMCAS), Tel Aviv, Israel, 5 July 2011; pp. 1-3.

35. Gramotnev, D.K.; Bozhevolnyi, S.I. Plasmonics beyond the diffraction limit. Nat. Photonics 2010, 4, 83-91. [CrossRef]

36. Economou, E.N. Surface plasmons in thin films. Phys. Rev. 1969, 182, 539. [CrossRef] 
37. Maier, S.A.; Kik, P.G.; Atwater, H.A.; Meltzer, S.; Harel, E.; Koel, B.E.; Requicha, A.A.G. Local detection of electromagnetic energy transport below the diffraction limit in metal nanoparticle plasmon waveguides. Nat. Mater. 2003, 2, 229-232. [CrossRef]

38. Vernon, K.C.; Gramotnev, D.K.; Pile, D.F. Adiabatic nanofocusing of plasmons by a sharp metal wedge on a dielectric substrate. J. Appl. Phys. 2007, 101, 104312. [CrossRef]

39. Gielis, J. A generic geometric transformation that unifies a wide range of natural and abstract shapes. Am. J. Bot. 2003, 90, 333-338. [CrossRef] [PubMed]

40. Yousefi, L. Highly directive hybrid plasmonic leaky wave optical nano-antenna. Prog. Electromagn. Res. Lett. 2014, 50, 85-90. [CrossRef]

41. Alam, M.Z. Hybrid Plasmonic Waveguides: Theory and Applications; University of Toronto: Toronto, ON, Canada, 2012.

42. Ctyrokỳ, J.; Kwiecien, P.; Richter, I. Analysis of hybrid dielectric-plasmonic slot waveguide structures with 3D Fourier Modal Methods. J. Eur. Opt. Soc.-Rapid Publ. 2013, 8, 13024. [CrossRef]

43. Yang, Y.; Li, Q.; Qiu, M. Broadband nanophotonic wireless links and networks using on-chip integrated plasmonic antennas. Sci. Rep. 2016, 6, 19490. [CrossRef]

44. Yousefi, L.; Foster, A.C. Waveguide-fed optical hybrid plasmonic patch nano-antenna. Opt. Express 2012, 20, 18326-18335. [CrossRef] [PubMed]

45. CST Microwave Studio CST of America, Inc. Available online: http:/ / www.cst.com (accessed on 17 September 2021).

46. Haque, A.; Reza, A.W.; Kumar, N.; Ramiah, H. Slotting effect in designing circular edge bow-tie nano antenna for energy harvesting. In Proceedings of the 2015 IEEE Conference on Open Systems (ICOS), Melaka, Malaysia, 24-26 August 2015; pp. $46-50$.

47. Saad-Bin-Alam, M.; Khalil, M.I.; Rahman, A.; Chowdhury, A.M. Hybrid Plasmonic Waveguide Fed Broadband Nanoantenna for Nano photonic Applications. IEEE Photonics Technol. Lett. 2015, 27, 1092-1095. [CrossRef]

48. Bozzetti, M.; de Candia, G.; Gallo, M.; Losito, O.; Mescia, L.; Prudenzano, F. Analysis and design of a solar rectenna. In Proceedings of the IEEE International Symposium on Industrial Electronics (ISIE 2010), Bari, Italy, 4-7 July 2010; pp. 2001-2004.

49. Nourmohammadi, A.; Nikoufard, M. Ultra-Wideband Photonic Hybrid Plasmonic Horn Nanoantenna with SOI Configuration. Silicon 2020, 12, 193-198. [CrossRef]

50. Sharma, P.; Vishwakarma, D.K. Long Range Multilayer Hybrid Plasmonic Waveguide Components and Integrated Circuit. IEEE Trans. Nanotechnol. 2019, 18, 940-947. [CrossRef]

51. Malheiros-Silveira, G.N.; Wiederhecker, G.S.; Hernández-Figueroa, H.E. Dielectric resonator antenna for applications in nanophotonics. Opt. Express 2013, 21, 1234-1239. [CrossRef]

52. Nikoufard, M.; Nourmohammadi, A.; Esmaeili, S. Hybrid Plasmonic Nanoantenna with the Capability of Monolithic Integration with Laser and Photodetector on InP Substrate. IEEE Trans. Antennas Propag. 2018, 66, 3-8. [CrossRef]

53. Balanis, C.A. Antenna Theory: Analysis and Design, 4th ed.; John Wiley \& Sons: New York, NY, USA, 2016. 